\title{
Tensile Behavior of Ferrite-martensite Dual Phase Steels with Nano-precipitation of Vanadium Carbides
}

\author{
Naoya KAMIKAWA, ${ }^{1) *}$ Masahiro HIROHASHI, ${ }^{2)}$ Yu SATO, ${ }^{3)}$ Elango CHANDIRAN, ${ }^{4)}$ Goro MIYAMOTO ${ }^{5)}$ and \\ Tadashi FURUHARA ${ }^{5)}$
}

1) Department of Intelligent Machines and System Engineering, Graduate School of Science and Technology, Hirosaki University, 3 Bunkyo-cho, Hirosaki, Aomori, 036-8561 Japan.

2) Formerly Graduate Student, Tohoku University. Now at Kobe Steel Ltd., 15 Kinugaoka, Moka, Tochigi, 321-4367 Japan.

3) Formerly Graduate Student, Tohoku University. Now at Aishin Seiki Co. Ltd., 2-1 Asahi-machi, Kariya, Aichi, $448-8650$ Japan.

4) Graduate Student, Tohoku University, 2-1-1 Katahira, Aoba-ku, Sendai, Miyagi, 980-8577 Japan.

5) Institute for Materials Research, Tohoku University, 2-1-1 Katahira, Aoba-ku, Sendai, Miyagi, 980-8577 Japan.

(Received on March 9, 2015; accepted on April 17, 2015)

\begin{abstract}
This paper reports the effect of nano-precipitation strengthening of ferrite on the tensile behavior of ferrite-martensite dual phase (DP) steels. Samples of ferrite-martensite DP steel containing a dispersion of nano-sized vanadium carbides (VCs) in the ferrite phase were produced by interphase precipitation and quenching of a $\mathrm{V}$-added low carbon steel, and the mechanical properties are compared with those of conventional ferrite-martensite DP samples without VC particles. Both the yield stress and the ultimate tensile strength are significantly increased by nano-VC precipitates. For ferrite volume fractions of $20-50 \%$ a dispersion of VCs results in only a small change in the elongation, whereas for ferrite volume fractions of above $50 \%$ both uniform and post-uniform elongations are decreased by a VC dispersion. It is suggested that dispersion of nano-precipitates in ferrite is an effective approach to simultaneously improve the strength and the strength-ductility balance of DP steels. Digital image correlation (DIC) analysis demonstrates that the ferrite phase is more deformed than the martensite phase in both VC-free and VC-dispersed DP samples, but that such strain partitioning is less pronounced in the VC dispersion-hardened samples. It is found that the stress-strain relationship of DP samples can reasonably be explained based on a law of mixtures using partitioned strain and stress values as estimated from the DIC analysis.
\end{abstract}

KEY WORDS: dual phase (DP) steel; interphase precipitation; vanadium carbides (VC); mechanical property; digital image correlation (DIC); strain and stress partitioning.

\section{Introduction}

Ferrite-martensite dual phase (DP) steels, composed of soft ferrite and hard martensite phases, are a category of commercially available advanced high-strength steels with good combination of high strength and excellent formability. ${ }^{1-3)}$ The mechanical characteristics of ferrite-martensite DP steels are a low yield stress accompanied by continuous yielding, a high work hardening rate, a low yield ratio (the ratio of yield stress to ultimate tensile strength) and a large uniform elongation. ${ }^{3-5)}$ However, one drawback of these steels is their small post-uniform elongation due to the large difference in strength between the ferrite and martensite phases. In contrast, nano-precipitated ferrite steels produced by interphase precipitation ${ }^{6,7)}$ are well known commercial steels having both high strength and good formability. This type of steel has a structure consisting of single phase ferrite containing a dispersion of nano-sized alloy carbides. The stress-strain curve of nano-precipitated steels is characterized by a high yield stress, a low work hardening rate (i.e. high yield ratio), a relatively small uniform elongation and

\footnotetext{
* Corresponding author: E-mail: kamikawa@hirosaki-u.ac.jp DOI: http://dx.doi.org/10.2355/isijinternational.ISIJINT-2015-106
}

a large post-uniform elongation. ${ }^{10,11)}$ However, unlike ferritemartensite DP steels, the uniform elongation of interphaseprecipitated steels is not so high.

It is interesting to note that ferrite-martensite DP steels and nano-precipitated ferrite steels have both advantages and disadvantages in their stress-strain behavior, with specific mechanical characteristics that are complementary. A combination of structural characteristics of ferrite-martensite DP steels and nano-precipitated steels might therefore yield a steel where the disadvantages of ferrite-martensite DP steels are compensated by the advantages of interphaseprecipitated steels, and vice versa. The motivation of the present work is the establishment of a strategy for production of such new high-strength steels, so-called "nano-precipitated DP steels", which is defined as ferrite-martensite DP steels containing a dispersion of nano-sized precipitates in the ferrite constituent phase. This idea has previously been proposed, and applied commercially in the production of wheel discs for automobiles. ${ }^{12,13)}$ The detailed deformation mechanisms of these steels are, however, not understood very well.

Mechanical properties of DP steels depend on several structural parameters, e.g. the volume fraction, ${ }^{14-18)}$ the distribution (size, morphology, connectivity, etc.) ${ }^{14,17,19-22)}$ and 
the constituent properties (strength, formability, etc.) ${ }^{23-30)}$ of the ferrite/martensite phases. In order to understand the deformation mechanisms of nano-precipitated DP steels, the effect of these factors on mechanical properties should systematically be investigated. The specific objective of the present work is to study the stress-strain behavior of ferritemartensite DP steels containing a dispersion of nano-sized vanadium carbides (VC) in the ferrite, mainly focusing on the effect of the volume fraction of ferrite/martensite phases. Some of the results reported in this paper have already been published in a conference proceeding, ${ }^{31)}$ but here we present the effect of nano-precipitation in ferrite on mechanical properties of ferrite-martensite DP steels in a more systematic manner.

\section{Experimental}

\subsection{Sample Preparation}

In the present study six different steels were used, as listed in Table 1. For all steels, as-cast ingots were first heated at $1180^{\circ} \mathrm{C}$ for $1 \mathrm{~h}$ and then hot-rolled at the finishing rolling temperature above $900^{\circ} \mathrm{C}$, followed by air cooling. The hotrolled slabs were homogenized in vacuum at $1150^{\circ} \mathrm{C}$ for 96 $\mathrm{h}$ to reduce solidification segregation.

The $0.1 \mathrm{C}-0.4 \mathrm{~V}$ steel was used to produce ferrite-martensite DP steels with dispersion of nano-sized vanadium carbide (VC) particles, in which the amounts of carbon and vanadium are almost identical in atomic percentage. Using a thermodynamics calculation software Thermo-Calc, the solid solution temperature of the vanadium carbo-nitrides in austenite and the $\mathrm{Ae}_{1}$ temperature at para-equilibrium were calculated to be $1043^{\circ} \mathrm{C}$ and $697^{\circ} \mathrm{C}$, respectively. The homogenized samples were austenitized and solution-treated at $1100^{\circ} \mathrm{C}$ for $600 \mathrm{~s}$ in an electric furnace in vacuum, and then immediately soaked in a salt bath at a set temperature of $690^{\circ} \mathrm{C}$ (below $\mathrm{Ae}_{1}$ in para-equilibrium) to promote a ferrite transformation accompanied by interphase precipitation of VC particles. ${ }^{32)}$ The volume fraction of $\mathrm{VC}$ precipitates is expected to be $0.78 \%$ at $690^{\circ} \mathrm{C}$ in the equilibrium condition. The isothermal holding at $690^{\circ} \mathrm{C}$ was carried out for different holding periods, in each case followed by water-quenching, to obtain ferrite-martensite DP structures with different volume fractions of the ferrite phase. A single phase martensite structure was also obtained by water-quenching immediately after austenitization treatment at $1100^{\circ} \mathrm{C}$.

Five different V-free carbon steels were also used to produce ferrite-martensite DP samples without dispersion of VC particles. For the $0.025 \mathrm{C}, 0.05 \mathrm{C}$ and $0.075 \mathrm{C}$ steels, the homogenized samples were austenitized at $1000^{\circ} \mathrm{C}$ for 600 $\mathrm{s}$, and immediately soaked in a salt bath for $1.8 \mathrm{ks}$ at $765^{\circ} \mathrm{C}$ (in the austenite/ferrite two-phase region), followed by water quenching. These heat treatment conditions and chemical compositions were chosen to produce ferritemartensite DP steels with different volume fractions of ferrite/martensite and similar carbon content in the martensite $(\sim 0.1 \mathrm{mass} \% \mathrm{C})$. For the $0.004 \mathrm{C}$ steel, after austenitization at $1000^{\circ} \mathrm{C}$ for $600 \mathrm{~s}$, the samples were isothermally transformed at $690^{\circ} \mathrm{C}$ for $1.8 \mathrm{ks}$, followed by water quenching to produce a single phase ferrite structure. For the $0.1 \mathrm{C}$ steel, samples were immediately water-quenched after austenitization at $1000^{\circ} \mathrm{C}$ to produce a single phase martensite structure.

\subsection{Microstructural Observation}

Microstructures of the obtained samples were characterized by optical microscopy, scanning electron microscopy (SEM) and transmission electron microscopy (TEM). Cross sections, perpendicular to the transverse direction of the original hot-rolled samples, were prepared for the observations.

From the optical microscopy images, the volume fraction of ferrite $\left(V_{F}\right)$ was measured using point counting method. Orientation measurements by electron backscatter diffraction (EBSD) were carried out using a TSL OIM system attached to a JEOL JSM-7001F SEM. From the EBSD data, the ferrite grain size was determined using an intercept method, where boundaries with misorientation angles below $2^{\circ}$ were not taken into account to remove errors in the determination of very low-angle boundaries. The TEM observations were carried out using a FEI CM300 operated at 300 $\mathrm{kV}$. Precipitation structures in the ferrite phase in the $\mathrm{V}$-added steel were characterized by dark-field imaging using diffraction spots from the VC particles. ${ }^{10,33)}$

\subsection{Mechanical Testing}

Hardness measurements were carried out using a Vickers hardness tester (Matsuzawa MMT-X7). The hardness of individual ferrite and martensite phases were measured using small loads of 5-100 gf. The total hardness of the samples was also measured using a load of $1 \mathrm{kgf}$. Tensile specimens with the gauge length of $4 \mathrm{~mm}$, width of $1 \mathrm{~mm}$ and thickness of $0.8 \mathrm{~mm}$ were prepared with the tensile axis parallel to the rolling direction of the original hot-rolled samples. The tensile tests at room temperature were carried out using a Shimadzu AG-100kNXplus system, at a constant crosshead speed of $0.2 \mathrm{~mm}$ minute ${ }^{-1}$, corresponding to an initial strain rate of $8.3 \times 10^{-4} \mathrm{~s}^{-1}$. Tensile elongation was measured by a Shimadzu DVE-101 non-contact video extensometer.

\subsection{Strain Distribution Measurement}

The local strain distribution introduced into ferrite/martensite phases during tensile testing was quantified using a digital image correlation (DIC) technique. ${ }^{34,35)}$ Tensile specimens with the same gauge dimensions described in Section 2.3 were prepared, and the observation surfaces were mechanically-polished and etched. The tensile tests were carried in-situ using JEOL JSM-7001F SEM equipped with a tensile test stage. In this experiment, the tests were inter-

Table 1. Chemical compositions of V-added and V-free steels studied (in mass\%).

\begin{tabular}{ccccccccccc}
\hline Steel type & $\mathrm{C}$ & $\mathrm{Mn}$ & $\mathrm{V}$ & $\mathrm{Si}$ & $\mathrm{P}$ & $\mathrm{S}$ & $\mathrm{N}$ & $\mathrm{Ti}$ & $\mathrm{Fe}$ \\
\hline $\begin{array}{c}\text { V-added steel } \\
\text { 0.1C-0.4V }\end{array}$ & 0.097 & 1.49 & 0.43 & 0.016 & $<0.002$ & 0.0007 & 0.0013 & $<0.002$ & Bal. \\
V-free steel & & & & & & & & & & \\
$0.1 \mathrm{C}$ & 0.098 & 1.50 & $<0.003$ & 0.049 & $<0.002$ & 0.0007 & 0.0009 & $<0.002$ & Bal. \\
$0.075 \mathrm{C}$ & 0.076 & 1.48 & $<0.003$ & 0.049 & $<0.002$ & 0.0027 & 0.0008 & $<0.002$ & Bal. \\
$0.05 \mathrm{C}$ & 0.049 & 1.48 & $<0.003$ & 0.050 & $<0.002$ & 0.0027 & 0.0010 & $<0.002$ & Bal. \\
$0.025 \mathrm{C}$ & 0.025 & 1.49 & $<0.003$ & 0.050 & $<0.002$ & 0.0027 & 0.0010 & $<0.002$ & Bal. \\
$0.004 \mathrm{C}$ & 0.0039 & 1.49 & $<0.003$ & 0.049 & $<0.002$ & 0.0024 & 0.0010 & $<0.002$ & Bal. \\
\hline
\end{tabular}


rupted without unloading at different nominal strains, to allow SEM images of the sample surface to be taken at each strain. The images, with a size of $2560 \times 2048$ pixels, were taken at a magnification of $200 \times$, corresponding to a spatial resolution of approximately $0.23 \mu \mathrm{m}$ per pixel. From these SEM images, DIC analysis was carried out using a commercially available software package (Correlated Solutions VIC-2D) to obtain the local strain on the tensile sample surface for each image captured. For DIC analysis, the subset size was set as $199 \times 199$ pixels and the correlation step size was chosen to be 2 pixels. Large strain deformation was quantified using the incremental correlation mode in the software. From the strain components determined by DIC software, the von Mises equivalent strain was calculated using the following standard equation,

$$
\varepsilon_{e q}=\sqrt{\frac{2}{3}\left(\varepsilon_{x x}{ }^{2}+\varepsilon_{y y}{ }^{2}+\varepsilon_{z z}{ }^{3}\right)+\frac{1}{3}\left(\gamma_{x y}{ }^{2}+\gamma_{y z}{ }^{2}+\gamma_{z x}{ }^{2}\right)}
$$

where $\varepsilon_{x x}$ is the normal strain component along the x-axis (parallel to the tensile axis), $\varepsilon_{y y}$ is the normal strain component along the y-axis (perpendicular to the tensile axis), $\varepsilon_{z z}$ is the normal strain component along the z-axis, $\gamma_{x y} \gamma_{y z}$ and $\gamma_{z x}$ are the shear strain components on the $\mathrm{x}-\mathrm{y}, \mathrm{y}-\mathrm{z}$ and $\mathrm{x}-\mathrm{z}$ planes, respectively. In the VIC-2D DIC system, however, only the $\varepsilon_{x x}, \varepsilon_{y y}$ and $\gamma_{x y}$ can be determined. We assume therefore that constant volume conditions are satisfied, i.e. $\mathcal{E}_{z z}=$ $-\varepsilon_{x x}-\varepsilon_{y y}$, and that $\gamma_{y z}$ and $\gamma_{z x}$ are zero. Thus, the equivalent strain can be calculated as follows,

$$
\varepsilon_{e q}=\sqrt{\frac{4}{3}\left(\varepsilon_{x x}{ }^{2}+\varepsilon_{x x} \varepsilon_{y y}+\varepsilon_{y y}{ }^{2}\right)+\frac{1}{3} \gamma_{x y}{ }^{2}}
$$

\section{Results}

\subsection{Microstructures}

The steel type and heat treatment conditions for the obtained samples are summarized in Table 2 . The volume fraction $\left(V_{F}\right)$ and grain size $\left(d_{F}\right)$ of the ferrite is also listed in the table.

Figure 1 shows optical microscopy images of DP samples with different ferrite volume fractions for both V-added and V-free steels. The areas of bright and dark contrast in the images correspond to ferrite and martensite phases, respectively. In the $\mathrm{V}$-added steel, the holding period of the isothermal treatment at $690^{\circ} \mathrm{C}$ has been controlled to change the volume fraction of ferrite. Isolated ferrite grains are surrounded by martensite in the sample with $V_{F}=24 \%$ (Fig. 1(a)). In the sample with $V_{F}=48 \%$ (Fig. 1(b)), the ferrite and martensite phases are relatively uniformly distributed, although the individual martensite regions are somewhat large. In the sample with $V_{F}=71 \%$ (Fig. 1(c)), most martensite regions are surrounded by ferrite grains and are isolated from each other. Figs. 1(d)-1(f) show the microstructures of the V-free DP steels. The volume fraction and distribution of ferrite/martensite phases are quite similar to those in the V-added steel, but the ferrite grain sizes in the V-free samples are larger than those in the V-added samples. This might affect the mechanical properties of DP samples, however we assume here that the effect of ferrite grain boundaries on the mechanical properties is less significant than the effect of the ferrite/martensite interfaces.

We have confirmed by TEM observations the occurrence of interphase precipitation of VC particles in the ferrite phases in the $\mathrm{V}$-added steel transformed at $690^{\circ} \mathrm{C}$. Figure 2(a) is a dark field TEM image of interphase-precipitated VCs in the ferrite phase in the V-added sample transformed
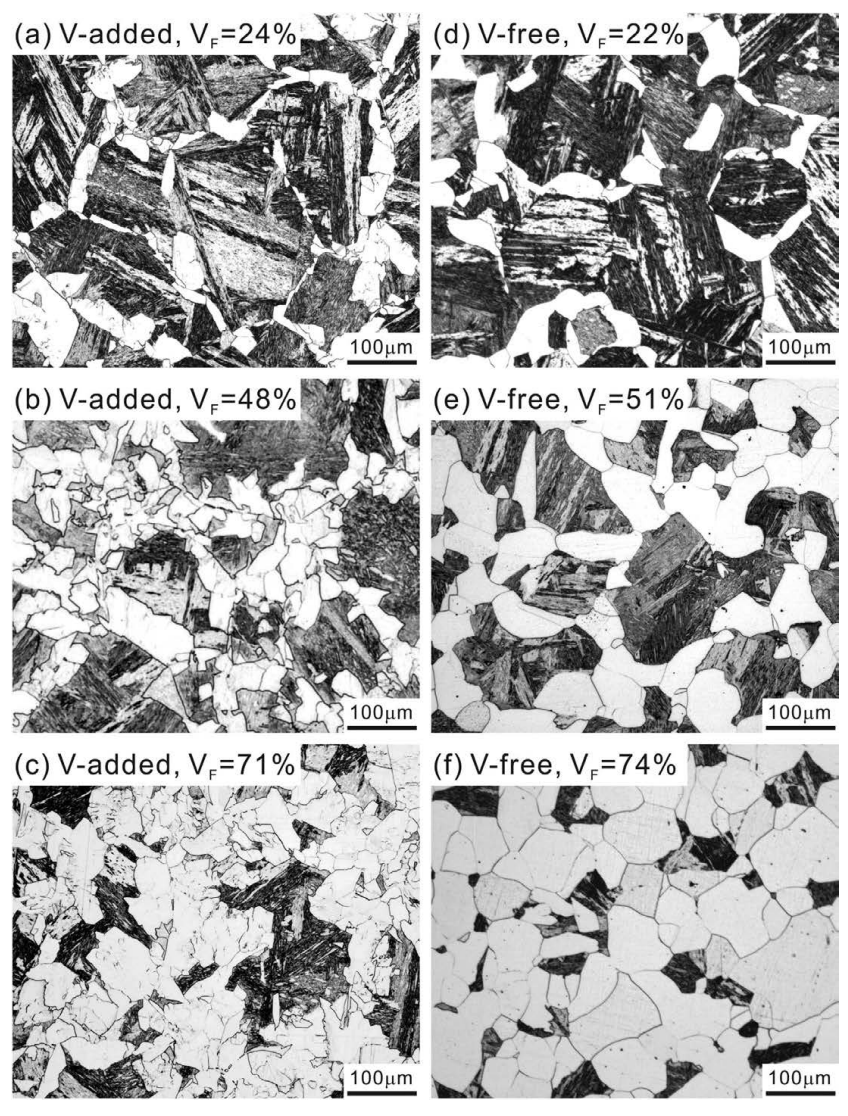

Fig. 1. Optical microscopy images of ferrite-martensite DP steels with different volume fractions of ferrite. (a-c) V-added and $(\mathrm{d}-\mathrm{f}) \mathrm{V}$-free samples. The volume fraction of ferrite is denoted as $V_{F}$.

\begin{tabular}{|c|c|c|c|c|c|c|c|}
\hline Steel type & & Heat treatment & $\begin{array}{l}V_{F} \\
\%\end{array}$ & $\begin{array}{c}\mathrm{d}_{\mathrm{F}} \\
\mu \mathrm{m}\end{array}$ & $\begin{array}{c}\mathrm{HV}_{\text {total }} \\
\mathrm{kgf} \mathrm{mm}^{-2}\end{array}$ & $\begin{array}{c}\mathrm{HV}_{\mathrm{F}} \\
\mathrm{kgf} \mathrm{mm}^{-2}\end{array}$ & $\begin{array}{c}\mathrm{HV}_{\mathrm{M}} \\
\mathrm{kgf} \mathrm{mm} \mathrm{mm}^{-2}\end{array}$ \\
\hline \multirow[t]{5}{*}{ V-added steel } & $0.1 \mathrm{C}-0.4 \mathrm{~V}$ & $1100^{\circ} \mathrm{C} 600 \mathrm{~s}+$ water quenching (WQ) & 0 & - & 376 & - & 365 \\
\hline & $0.1 \mathrm{C}-0.4 \mathrm{~V}$ & $1100^{\circ} \mathrm{C} 600 \mathrm{~s}+690^{\circ} \mathrm{C} 90 \mathrm{~s}+\mathrm{WQ}$ & 24 & 16 & 330 & 272 & 364 \\
\hline & $0.1 \mathrm{C}-0.4 \mathrm{~V}$ & $1100^{\circ} \mathrm{C} 600 \mathrm{~s}+690^{\circ} \mathrm{C} 150 \mathrm{~s}+\mathrm{WQ}$ & 48 & 18 & 305 & 274 & 367 \\
\hline & $0.1 \mathrm{C}-0.4 \mathrm{~V}$ & $1100^{\circ} \mathrm{C} 600 \mathrm{~s}+690^{\circ} \mathrm{C} 210 \mathrm{~s}+\mathrm{WQ}$ & 71 & 19 & 310 & 260 & 363 \\
\hline & $0.1 \mathrm{C}-0.4 \mathrm{~V}$ & $1100^{\circ} \mathrm{C} 600 \mathrm{~s}+690^{\circ} \mathrm{C} 1800 \mathrm{~s}+\mathrm{WQ}$ & 100 & 20 & 275 & 264 & - \\
\hline \multirow[t]{5}{*}{ V-free steel } & $0.1 \mathrm{C}$ & $1000^{\circ} \mathrm{C} 600 \mathrm{~s}+\mathrm{WQ}$ & 0 & - & 362 & - & 354 \\
\hline & $0.075 \mathrm{C}$ & $1000^{\circ} \mathrm{C} 600 \mathrm{~s}+765^{\circ} \mathrm{C} 1800 \mathrm{~s}+\mathrm{WQ}$ & 22 & 35 & 270 & 131 & 347 \\
\hline & $0.05 \mathrm{C}$ & $1000^{\circ} \mathrm{C} 600 \mathrm{~s}+765^{\circ} \mathrm{C} 1800 \mathrm{~s}+\mathrm{WQ}$ & 51 & 39 & 154 & 129 & 353 \\
\hline & $0.025 \mathrm{C}$ & $1000^{\circ} \mathrm{C} 600 \mathrm{~s}+765^{\circ} \mathrm{C} 1800 \mathrm{~s}+\mathrm{WQ}$ & 74 & 49 & 133 & 132 & 352 \\
\hline & $0.004 \mathrm{C}$ & $1000^{\circ} \mathrm{C} 600 \mathrm{~s}+690^{\circ} \mathrm{C} 1800 \mathrm{~s}+\mathrm{WQ}$ & 100 & 48 & 104 & 141 & - \\
\hline
\end{tabular}

Table 2. Heat treatment conditions, volume fraction of ferrite, ferrite grain size and hardness for samples obtained. 


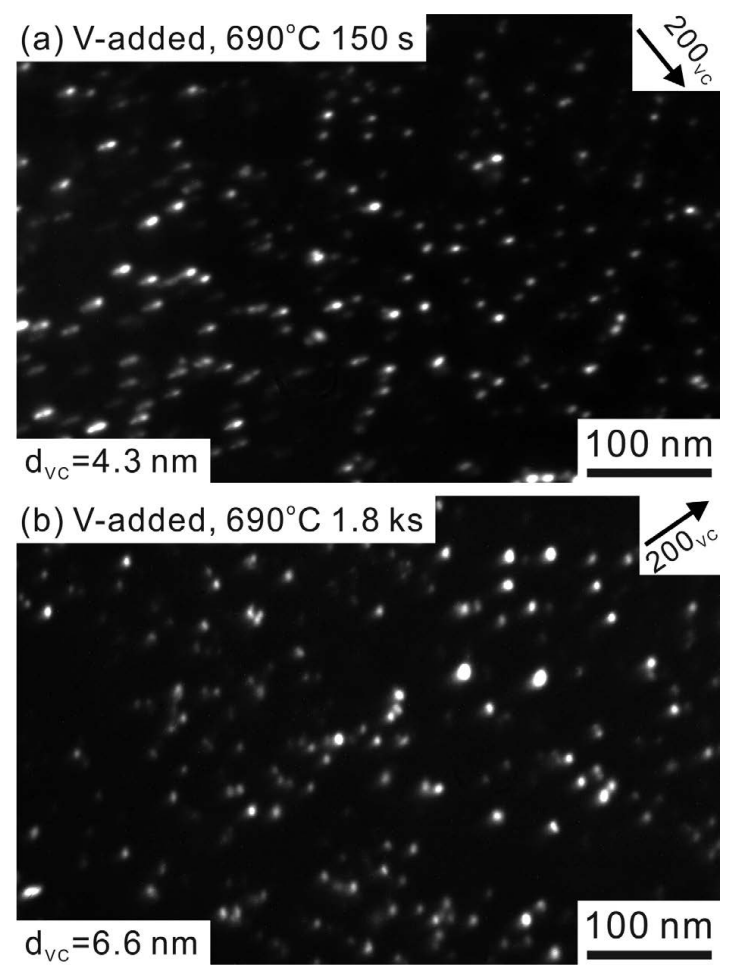

Fig. 2. Dark field TEM images of VC particles in ferrite phase in the $\mathrm{V}$-added samples transformed at $690^{\circ} \mathrm{C}$ for (a) $150 \mathrm{~s}$ and (b) $1.8 \mathrm{ks}$. The images were taken under a diffraction condition of $\mathrm{g}^{*}=200 \mathrm{vc}$.

at $690^{\circ} \mathrm{C}$ for $150 \mathrm{~s}\left(V_{F}=48 \%\right)$. The average diameter of the VCs was determined as $4.3 \mathrm{~nm}$. The precipitation structure of the $\mathrm{V}$-added sample transformed at $690^{\circ} \mathrm{C}$ for $1.8 \mathrm{ks}\left(V_{F}=\right.$ $100 \%$ ) is shown in Fig. 2(b), where the average diameter of the VCs was determined as $6.6 \mathrm{~nm}$, slightly larger than that of the sample transformed for $150 \mathrm{~s}$ (Fig. 2(a)), indicating that slight coarsening of $\mathrm{VC}$ particles took place during the prolonged holding at $690^{\circ} \mathrm{C}$.

\subsection{Vickers Hardness}

The hardness of individual ferrite and martensite phases, as well as the total hardness for the V-free and V-added samples, is plotted as a function of ferrite volume fraction in Figs. 3(a) and 3(b), respectively. The average hardness values are summarized in Table 2.

In the V-free steel (Fig. 3(a)), the total hardness of samples decreases with increasing volume fraction of ferrite, with the individual hardness of both the ferrite and martensite phases almost constant regardless of the ferrite volume fraction. The hardness of the ferrite is approximately 130 $\mathrm{HV}$, whereas the martensite hardness is about $350 \mathrm{HV}$, in good agreement with the hardness of as-quenched 0.1 mass $\%$ C martensite. ${ }^{36)}$ In contrast for the V-added steel (Fig. 3(b)), the ferrite hardness is much higher, with a constant value of approximately 260-270 $\mathrm{HV}$, due to precipitation strengthening of ferrite by interphase precipitation of $\mathrm{VC}$ particles. The observed constant value of the ferrite hardness shown in Fig. 3(b) suggests that the difference in diameter of VC particles observed in Fig. 2 does not significantly affect the hardness of the ferrite. The hardness of martensite in the V-added steel is measured to be constant at $360 \mathrm{HV}$, similar to that in the $\mathrm{V}$-free steel, indicating that the carbon content in martensite is kept at 0.1 mass $\% \mathrm{C}$. This should be due to the fact that carbon enrichment of the austenite phase did not occur during the ferrite transformation, presumably as the carbon atoms have mostly been consumed through
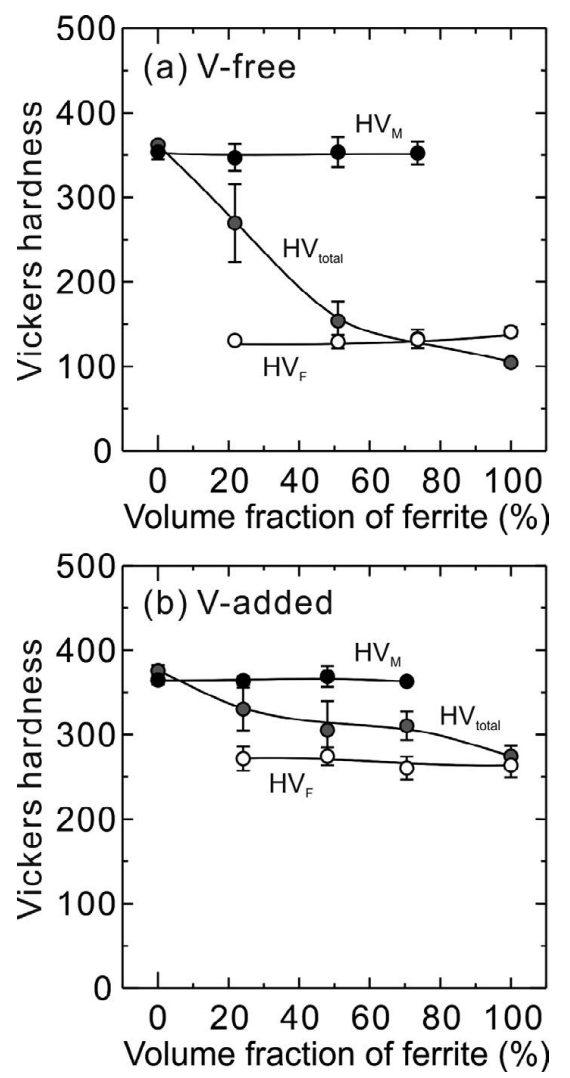

Fig. 3. Vickers hardness of (a) V-free and (b) V-added samples. $\mathrm{HV}_{\mathrm{F}}$ and $\mathrm{HV}_{\mathrm{M}}$ is the individual hardness of ferrite and martensite, respectively. $\mathrm{HV}_{\text {total }}$ is the total hardness measured using a load of $1 \mathrm{kgf}$.

interphase precipitation of VCs, with an fcc structure of the $\mathrm{NaCl}$ type, at austenite/ferrite interfaces.

\subsection{Stress-strain Behavior}

Nominal stress-strain curves for the V-free and V-added samples are shown in Figs. 4(a) and 4(b), respectively. From the stress-strain curves, $0.2 \%$ offset stress $\left(\sigma_{0.2}\right)$, ultimate tensile strength (UTS) $\left(\sigma_{\mathrm{UTS}}\right)$, uniform elongation, post-uniform elongation and total elongation have been determined and are plotted as a function of ferrite volume fraction in Fig. 5.

In the V-free steel, the as-quenched martensite sample $\left(V_{F}=\right.$ $0 \%$ ) shows the highest strength, and the strength decreases with increasing volume fraction of ferrite. The uniform elongation gradually increases with increasing volume fraction of ferrite. On the other hand, both the post-uniform and total elongations first decrease compared to the as-quenched martensite, reaching a minimum at $V_{F}=\sim 25 \%$, and then gradually increase with increasing volume fraction of ferrite. A qualitatively similar tendency in the dependence of strength and ductility on increasing volume fraction of ferrite can also be observed in the V-added steel. The stressstrain curve of the as-quenched martensite in the V-added steel is almost identical to that in the V-free steel. The strength decreases with increasing volume fraction of ferrite, as for the V-free steel, but the strength is higher in the $\mathrm{V}$-added steel than in the $\mathrm{V}$-free steel, due to precipitation strengthening of the ferrite by $\mathrm{VC}$ precipitates. There is no significant difference in either the uniform, the post-uniform or the total elongation at $V_{F}<50 \%$, but the elongation is much larger in the $\mathrm{V}$-free steel than in the $\mathrm{V}$-added steel for $V_{F}>50 \%$. 


\subsection{Strength-ductility Balance}

The balance between strength and ductility between the V-free and V-added samples in compared in Fig. 6, showing the balance of UTS vs uniform elongation, UTS vs postuniform elongation and UTS vs total elongation in Figs. 6(a), 6(b) and 6(c), respectively.

For both V-free and V-added steels, a similar tendency can be observed with respect to the volume fraction of ferrite. With regard to the strength-uniform elongation balance (Fig. 6(a)), the elongation increases for both V-free and V-
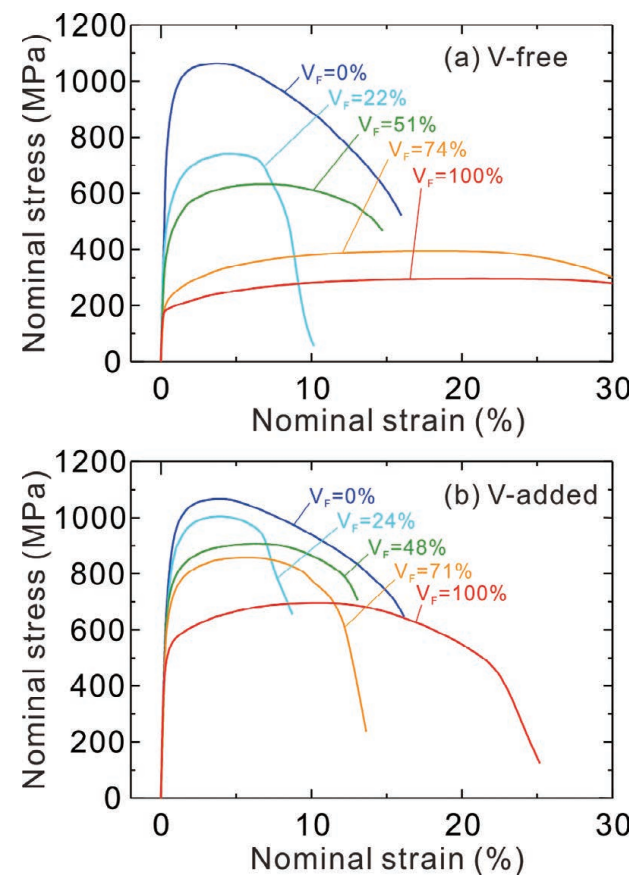

Fig. 4. Nominal stress-strain curves of (a) V-free and (b) V-added samples. The volume fraction of ferrite is indicated as $V_{F}$. added steels with increasing ferrite volume fraction, but the dual phase samples tend to show a better balance between strength and uniform elongation than the martensite or ferrite single phase samples. In contrast, the single phase samples show better balance between strength and post-uniform elongation than the dual phase samples (Fig. 6(b)). These tendencies correspond well with previous reports. ${ }^{37)}$

No difference in the strength-ductility balance is seen for the single phase martensite samples in the V-free and Vadded steels, but for the DP samples with $V_{F}$ of $20-50 \%$ containing a dispersion of $\mathrm{VC}$ particles an increase in strength without almost no loss of both uniform and postuniform elongation is seen, resulting in an improvement of the strength-ductility balance. However, for samples with $V_{F}$ of $70-100 \%$, the strength is significantly increased due to the VC dispersion, but the samples also show a significant decrease in uniform elongation. Note, however, that no big difference in the strength-uniform elongation balance between the $\mathrm{V}$-free and V-added steels is found. On the other hand, when the strength-post uniform elongation balance is compared, the data show a significant improvement in the VC dispersionhardened steels. As a result of this tendency in uniform and post-uniform elongation, the strength-total elongation balance (Fig. 6(c)) is also improved by the VC dispersion.

\section{Discussion}

The above results demonstrate that strengthening of ferrite by nano-precipitates in DP steels is an effective strategy to improve simultaneously both the strength and the strengthductility balance, and in particular the strength-post uniform elongation balance. In this section, we attempt to quantify the local deformation behavior between ferrite and martensite phases using the DIC technique. Based on these observations, the macroscopic stress-strain relationship determined by tensile test is then correlated with the local deformation behavior of the two phases.
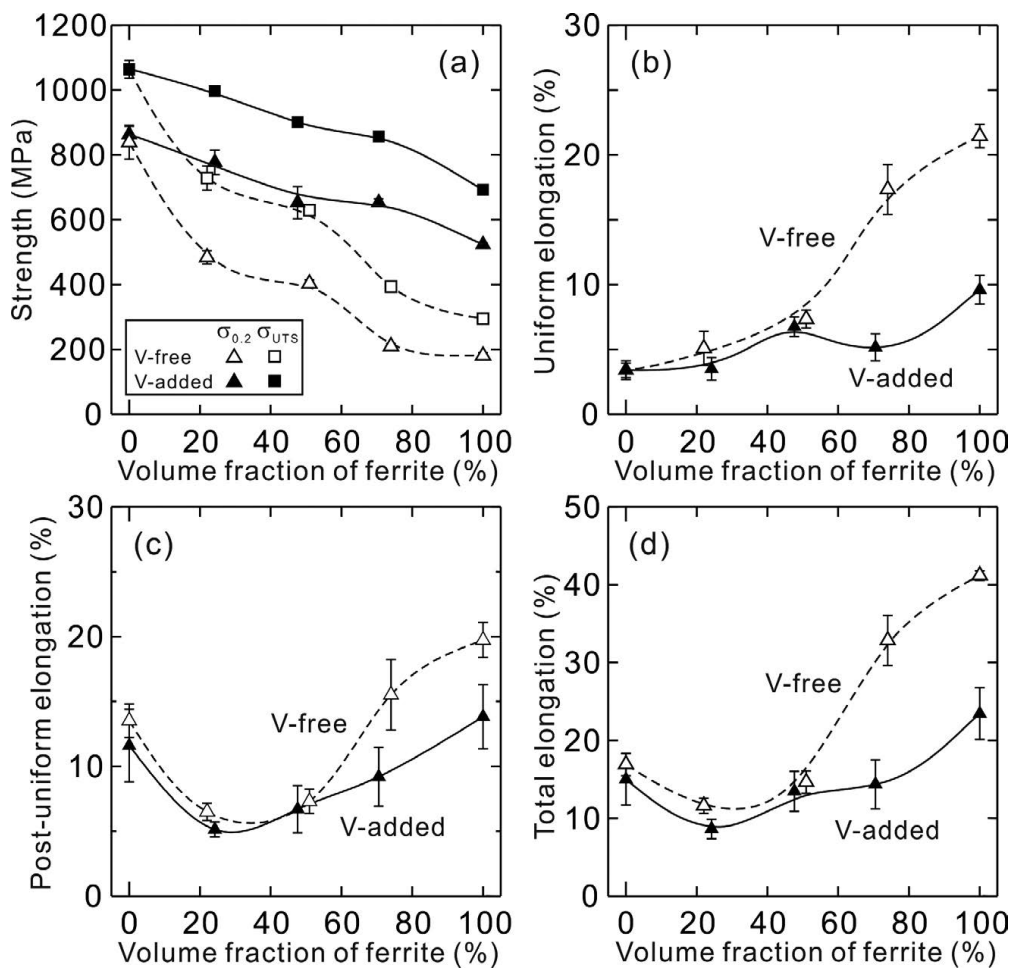

Fig. 5. Strength and ductility of V-free and V-added samples as a function of volume fraction of ferrite. (a) $0.2 \%$ proof stress and ultimate tensile strength, (b) uniform elongation, (c) post-uniform elongation, (d) total elongation. 

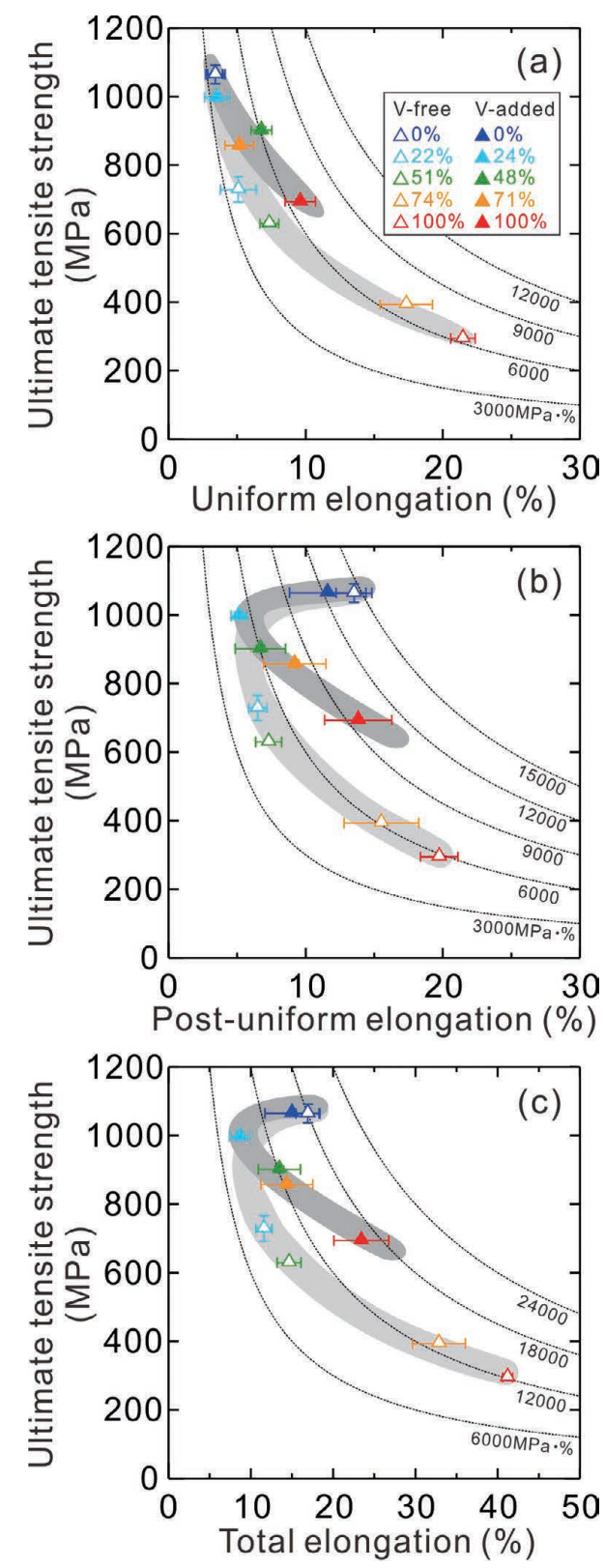

Fig. 6. Strength-ductility balance of V-free and V-added samples. (a) Ultimate tensile strength (UTS) vs uniform elongation, (b) UTS vs post-uniform elongation and (c) UTS vs total elongation.

\subsection{Strain Partitioning Analysis by DIC}

As ferrite-martensite DP steels are composed of softer ferrite and harder martensite phases, plastic flow may take place in the soft phase preferentially, resulting in heterogeneous deformation pattern in the strain between the two phases. Strain heterogeneity can also occur even within individual ferrite or martensite phases, depending on the orientation, size, morphology, etc. of each. As a result of such strain heterogeneity, internal stresses may also vary depending on the individual phases or grains. Such heterogeneities in strain and stress are called strain and stress partitioning, respectively. ${ }^{38,39)}$

Strain and stress partitioning between the phases in DP steels or other multiphase steels has experimentally been quantified by EBSD, ${ }^{40-42}$ in-situ neutron diffraction, ${ }^{42-44)}$ high-energy X-ray diffraction, ${ }^{38,45)} \mathrm{DIC}^{22,30,46-49)}$ and lithography. ${ }^{26,48,50)}$ In this study, DIC is applied to quantify strain partitioning between ferrite and martensite phases during insitu tensile tests carried out in a SEM. For this experiment

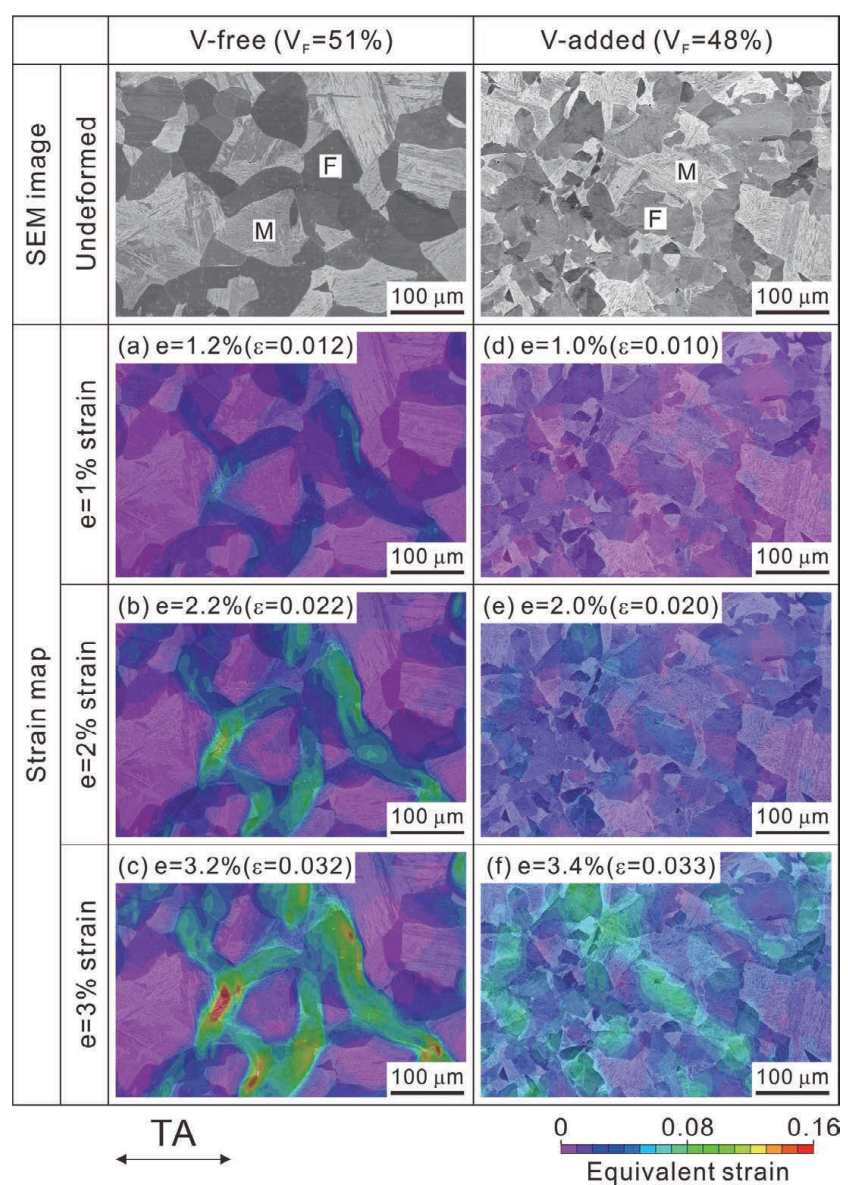

Fig. 7. Strain map obtained by DIC analysis for V-free and V-added DP samples with the ferrite volume fraction of $\sim 50 \%$.

and analysis, we choose $\mathrm{V}$-free and $\mathrm{V}$-added samples with $V_{F}=\sim 50 \%$, where the $\mathrm{V}$-added sample shows a higher strength while still retaining sufficient elongation compared with the V-free sample (Figs. 4 and 5).

Figure 7 shows the results of DIC analysis. SEM images in the undeformed state are indicated at the top of each column, where dark and bright contrast areas correspond to ferrite and martensite phases, respectively. The colored figures show equivalent strain distribution maps, superimposed on grey-scale SEM images, after deformation to nominal tensile strains of between approximately 1 and $3 \%$. In the $\mathrm{V}$-free steel, the strain distribution in the analyzed area is quite heterogeneous. It is clearly seen that deformation is concentrated in the ferrite phases, while the martensite phases seem to be hardly deformed. Strain heterogeneity becomes more enhanced with increasing the applied macroscopic strain (Figs. 7(a)-7(c)). Such strain partitioning between ferrite and martensite phases can also be observed in the V-added steel but is less pronounced (Figs. 7(d)-7(f)).

From the strain maps obtained in Fig. 7, strain distributions in the ferrite and martensite phases have been separated and are plotted as histograms in Fig. 8, in order to more quantitatively demonstrate the significant difference in strain partitioning between V-free and V-added steels. In the V-free steel, after $1 \%$ strain the distribution of strain in the martensite phase is located in the smaller strain region, while the strain in the ferrite phase is distributed in the larger strain region. Such partitioning becomes further enhanced with increasing tensile strain. From 1 to $3 \%$ deformation, the strain distribution of the martensite still remains located in the relatively small strain region, while in the ferrite phase a wide broadening in strain distribution is observed 


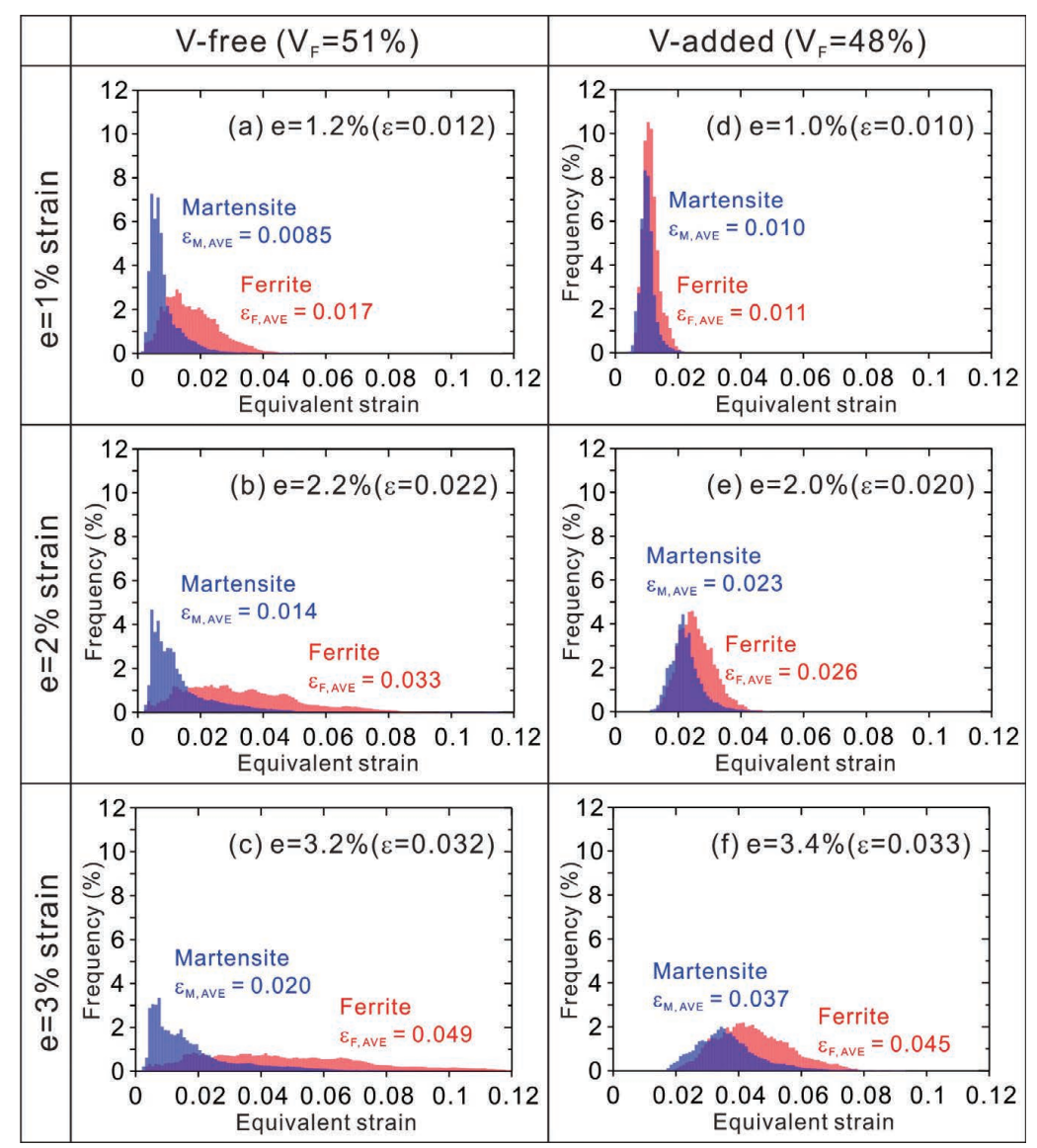

Fig. 8. Strain distribution obtained by DIC analysis for V-free and V-added DP samples with the ferrite volume fraction of $\sim 50 \%$. The strains introduced in ferrite and martensite phases are separated. The bin size of the distribution is an equivalent strain of 0.001 .

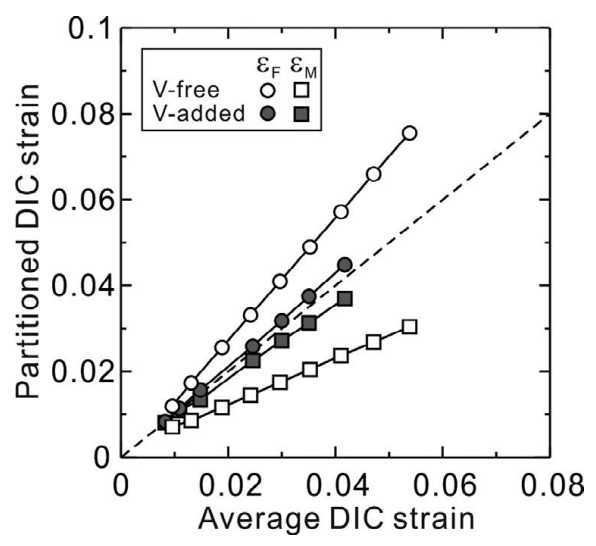

Fig. 9. Partitioned strain between ferrite and martensite phases, as a function of average equivalent strain estimated by DIC analysis.

from small to large strains. In contrast, in the V-added steel, the distributions of strain in the ferrite and martensite phases are rather similar. Moreover, the two distributions both show a gradual shift to larger strain levels with increasing applied strain, indicating that a more homogeneous deformation pattern is achieved in the V-added steel.

Figure 9 plots the average partitioned strain for the ferrite and martensite phases as a function of average equivalent strain, as estimated from the DIC analysis. For both the Vfree and V-added steels, the partitioned strain in the ferrite is larger than that in the martensite, and the difference in the partitioned strain between these two phases increases with increasing applied strain, as observed also in Fig. 8. How- ever, the difference in partitioned strain between the two phases is much smaller in the $\mathrm{V}$-added steel than in the $\mathrm{V}$ free steel. This plot confirms that strain partitioning between ferrite and martensite phases in DP steels is greatly suppressed by nano-precipitates in ferrite.

Suppression of strain partitioning can be understood by the decrease in the strength difference between ferrite and martensite. Similar tendencies have also been observed in other studies, ${ }^{26,30)}$ where the effect of tempering on strain partitioning has been investigated in ferrite-martensite DP steels. In such cases, a strength difference between the two phases was reduced by reducing the strength of the martensite, leading to a decrease in the overall strength of the DP steels. It should be emphasized, however, that in the current study the strength difference has been reduced by increasing the strength of ferrite, leading to a significant increase in the overall strength of the investigated DP steel, instead of degrading the strength. Thus, it is suggested that the proposed strategy is advantageous for a simultaneous improvement of strength and ductility or formability of DP steels.

\subsection{Correlation between Strain-stress Partitioning and Macroscopic Flow Stress}

To correlate the strain partitioning quantified by DIC analysis with the macroscopic stress-strain behavior, we try to calculate the stress-strain relationship. It is assumed here that the strain and stress in the DP samples can be expressed by a simple law of mixtures, ${ }^{51)}$

$$
\begin{gathered}
\varepsilon_{\mathrm{DP}}=V_{\mathrm{F}} \varepsilon_{\mathrm{F}}+\left(1-V_{\mathrm{F}}\right) \varepsilon_{\mathrm{M}} . \\
\sigma_{\mathrm{DP}}=V_{\mathrm{F}} \sigma_{\mathrm{F}}+\left(1-V_{\mathrm{F}}\right) \sigma_{\mathrm{M}}
\end{gathered}
$$



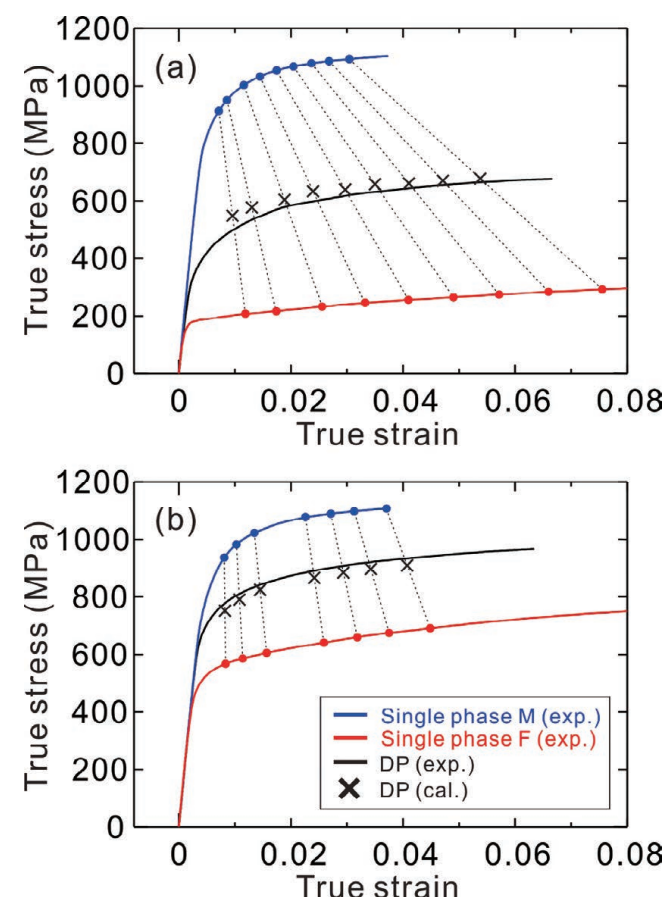

Fig. 10. Calculation of stress-strain relationship for DP samples with the ferrite volume fraction of $\sim 50 \%$ based on the law of mixtures. (a) V-free and (b) V-added samples.

where $\varepsilon_{\mathrm{DP}}, \varepsilon_{\mathrm{F}}$ and $\varepsilon_{\mathrm{M}}$ are the average strains, and $\sigma_{\mathrm{DP}}, \sigma_{\mathrm{F}}$ and $\sigma_{\mathrm{M}}$ are the average stresses in the DP samples, the ferrite and the martensite, respectively, and where $V_{\mathrm{F}}$ is the volume fraction of ferrite. To estimate the average stresses in the DP samples, the nominal stress-strain curves for single-phase ferrite or single-phase martensite in Fig. 4 were converted into true stress-strain curves and are plotted as red and blue lines in Fig. 10 for both V-free and V-added steels, respectively. From these curves, the average stress, i.e. the partitioned stress, in each phase of the DP samples has been determined and is plotted in the figure, based on the average partitioned strains determined by the DIC analysis (see Figs. 8, 9). It is clearly seen that the stress partitioning between the constituent phases is strongly affected by the nano-precipitates.

From the experimentally-determined partitioned strain and stress, the stress-strain relationship has been calculated based on Eqs. (3) and (4), and the values are plotted as black crosses in Fig. 10, demonstrating that this analysis can reasonably explain the flow curves of DP steels for both V-free and V-added steels. The estimated phase stress is plotted as a function of average equivalent strain in Fig. 11. The average stress in the martensite becomes slightly higher in the $\mathrm{V}$-added steel than in the $\mathrm{V}$-free steel, as more homogeneous deformation is introduced in the martensite in the V-added steel. However, it is seen that the increase in the stress supported by the ferrite phase is much more significant than that in martensite. Thus, it can be concluded that the significant increase in the flow stress, as well as in the yield stress in the V-added steel, should be dominated by the precipitation strengthening of the ferrite by nano-sized VC particles.

\subsection{Effect of Nano-precipitates on Work Hardening and Ductility of DP Samples}

One of the interesting findings obtained in this study is the improvement of the strength-ductility balance as well as the strength. In particular, for the cases of $V_{F}<50 \%$, the elongation of the DP samples only decreases by a small amount even after considerable strengthening by a dispersion of nano-precipitates. In this section, effect of nano-precipitates

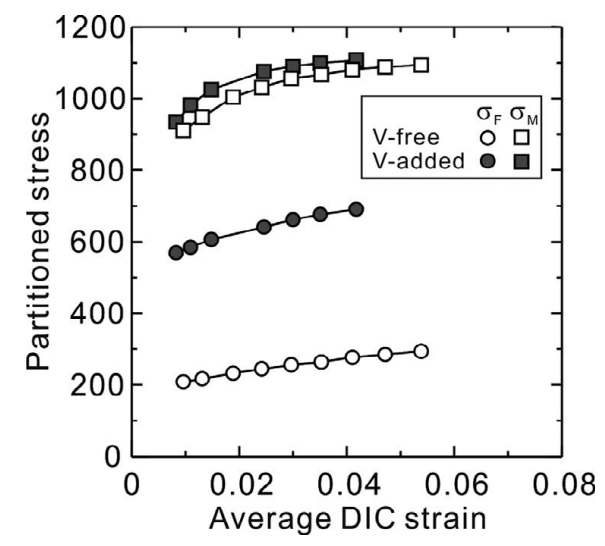

Fig. 11. Partitioned stress between ferrite and martensite phases, as a function of average equivalent strain estimated by DIC analysis.

on the ductility of DP steels is further discussed.

The ductility of metals is closely related to the work hardening behavior after yielding. It is well known that uniform elongation obtained by uniaxial tensile test can be determined by the plastic instability criterion. ${ }^{52)}$

$$
\sigma>\frac{d \sigma}{d \varepsilon}
$$

where $\sigma$ and $\varepsilon$ are the true stress and true strain, respectively, and $d \sigma / d \varepsilon$ is the work hardening rate. Once this equation is satisfied, macroscopic necking starts to occur. Here, the relationship between the flow stress and work hardening rate is compared for the samples in Fig. 4. To do this the nominal stress-strain curves were transformed into true stress-true strain curves by assuming a condition of constant volume, and work hardening rate curves were then obtained by differentiating the true stress with respect to the true strain.

Figure 12 shows curves for the work hardening rate in Vfree and $\mathrm{V}$-added samples with different volume fractions of ferrite. It is seen that in the samples in the range $V_{F}=0$ $50 \%$ (Figs. 12(a)-12(c)) there is no significant difference in the work hardening rate between the V-free and V-added steels. Although the strength of the $\mathrm{V}$-added steel is higher than that of the V-free sample, the onset of plastic instability occurs at a similar strain level, leading to similar uniform elongations between the V-free and V-added steels. On the other hand, in samples with $V_{F}>50 \%$ (Figs. 12(d)-12(e)), the work hardening rate in the $\mathrm{V}$-added steel is larger than in the V-free steel in the early stage of deformation. In particular, a significant difference in the work hardening rate between the V-free and V-added steels can be seen in the single-phase ferrite samples. However, in the later stage of deformation, the work hardening rate in the $\mathrm{V}$-added steels becomes smaller than that in the V-free steels, leading to the earlier onset of plastic instability and therefore a smaller uniform elongation in the V-added steel.

The difference in the work hardening rate between the Vfree and V-added steels can easily be understood in the single-phase martensite and ferrite samples in the following way. In the single-phase martensite (Fig. 12(a)), it is reasonable to expect a similar work hardening rate since the stressstrain curves are identical in the V-free and V-added samples. On the other hand, the work hardening rate of single-phase ferrite (Fig. 12(e)) is much higher in the V-added steel than in the V-free steel in the early stage of deformation. This can be understood by the effect of nano-precipitates on enhancing the work hardening rate. More specifically, uniformlydistributed nano-sized alloy carbides may act as sources for 

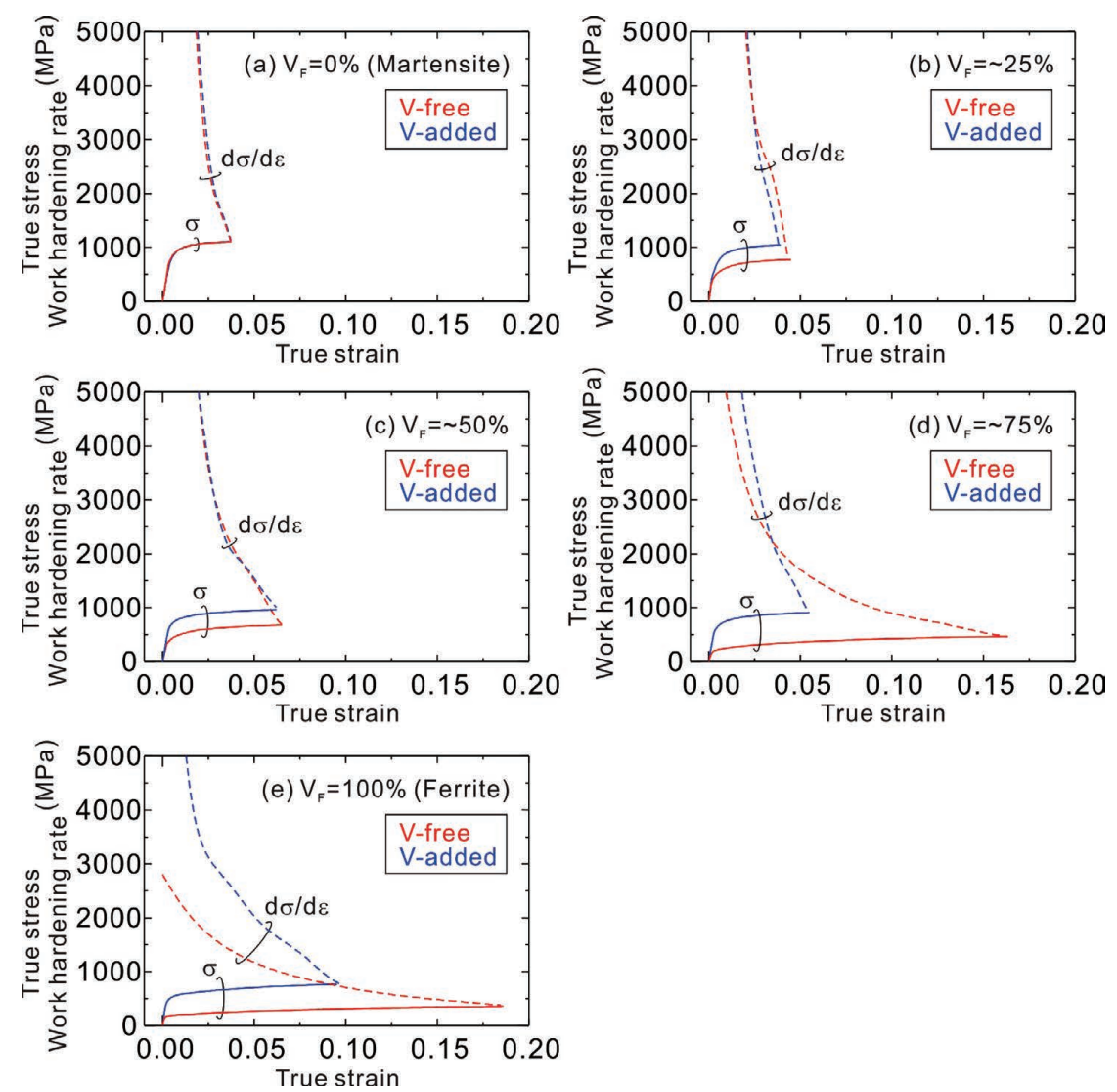

Fig. 12. True stress-strain curve and work hardening rate for the $\mathrm{V}$-free and $\mathrm{V}$-added samples. (a) $\mathrm{V}_{\mathrm{F}}=0 \%$ (single phase martensite), (b) $\mathrm{V}_{\mathrm{F}}=\sim 25 \%$, (c) $\mathrm{V}_{\mathrm{F}}=\sim 50 \%$, (d) $\mathrm{V}_{\mathrm{F}}=\sim 75 \%$ and (e) $\mathrm{V}_{\mathrm{F}}=100 \%$ (single phase ferrite).

dislocation multiplication, ${ }^{10,11,53)}$ leading to a rapid increase in dislocation density in the very early stages of tensile testing and therefore resulting in a higher work hardening rate in the V-added steel. However, such multiplied dislocations may easily interact and annihilate with each other, leading to enhanced dynamic recovery in the later stages of deformation. ${ }^{10,11)}$ On the contrary, in the V-free sample, dislocation multiplication may occur gradually, much more slowly than in the V-added steel, during which time dislocation cell structures are gradually formed within ferrite grains. ${ }^{10,11)}$ This can explain why the work hardening rate in the $\mathrm{V}$-added steel becomes smaller than in the V-free steel in the later stages of tensile deformation. Because the increase of strength due to the $\mathrm{VC}$ dispersion is significant, the plastic instability criterion is satisfied at a lower strain level, leading to less uniform elongation in the V-added steel.

The work hardening rate and uniform elongation of DP samples (Figs. 12(b)-12(d)) can in turn understood by taking account of the work hardening behavior of each constituent phase. We take the case of the samples with $V_{F}=\sim 50 \%$ (Fig. 12(c)) as an example. Since strain partitioning between two phases is suppressed by the VC dispersion, the local strain in the martensite is larger than in the V-added steel, which may lead to less work hardening in martensite. On the other hand, in the ferrite phase, the work hardening is enhanced by VC precipitation. Thus, enhanced work hardening in ferrite and less work hardening in martensite effectively cancelled each other out, leading to the obasevation of no significant change in the work hardening rate even in the case of a VC dispersion. The mechanical behavior of samples with $V_{F}$ of $\sim 25 \%$ and $\sim 75 \%$ may also be understood in a similar manner, by considering the relative effect of work hardening in the ferrite and martensite constituents.

The suppression of strain partitioning by a VC dispersion in ferrite can also be expected to have an important role in determining the post-uniform elongation after necking in a tensile test. As a result of a dispersion of nano-precipitates in ferrite, strain localization in the soft ferrite phase should also be less pronounced in the post-uniform deformation region. Thus, void or crack formation in the vicinity of ferrite/martensite interfaces might be retarded, which may in turn lead to a delay in the initiation of ductile fracture. This can be one possible reason why the post-uniform elongation of DP samples still remains at comparable level even though the strength is increased by the presence of a VC dispersion in the ferrite. Another reason might be enhanced recovery in the ferrite phase due to the nano-VC dispersion, ${ }^{10,11)}$ as discussed above, where dislocation annihilation may be enhanced significantly around nano-particles, thereby retarding dislocation accumulation and local stress concentration in the ferrite phase.

One interesting observation in terms of ductility is that the post-uniform elongation shows a minimum at $V_{F}=$ $\sim 25 \%$ in both V-free and V-added steels, while single-phase martensite or ferrite samples show very large post-uniform elongation. One possible reason would be that the presence of small amount of ferrite grains in the martensite matrix (see Figs. 1(a) and 1(d)) significantly enhances strain localization into ferrite phases, leading to accelerated void formation in the vicinity of ferrite/martensite interfaces. Another reason could be the fact that such small fraction of ferrite grains is preferentially nucleated at prior austenite grain boundaries in the martensite structure. Since prior austenite grain boundaries may act as sites for inhomogeneous deformation, strain partitioning could be more accelerated in the vicinity of ferrite grains in the vicinity of prior austenite grain boundaries.

To prove the above hypotheses, the effect of nanoprecipitates on the fracture behavior, such as void and crack 
initiation and growth of the samples should be investigated in detail. One powerful technique to clarify this issue will be in-situ observation of void formation during tensile test in SEM, combined with DIC analysis, which will be the topic of our future work.

\section{Conclusions}

In this study the effect of precipitation strengthening in ferrite on the tensile behavior of ferrite-martensite DP steels has been investigated. The results obtained are summarized as below.

(1) Dispersion of nano-VC precipitates in ferrite leads to a significant increase in strength in ferrite-martensite DP steels. It should be emphasized that this strength increase occurs with almost no loss of both uniform and total elongation for ferrite volume fractions of $20-50 \%$, while the uniform and total elongation are both larger in the VC-free samples compared to the VC-dispersion hardened samples for ferrite volume fractions of larger than $50 \%$.

(2) Analysis of the strength-elongation plots reveals that there is no significant difference in the strength-uniform elongation balance between VC-free and VC-dispersed samples, but that the strength-post uniform elongation balance is greatly improved by the presence of a VC dispersion. It is therefore suggested that precipitation strengthening of ferrite is an effective strategy to improve both the strength and the strength-ductility balance of ferrite-martensite DP steels.

(3) DIC analysis of in-situ tensile tests demonstrates that deformation is more localized in soft ferrite than in hard martensite for both the VC-free and VC-dispersed DP samples, i.e. the strain partitioning between the ferrite and martensite phases is clearly observed. However, precipitation strengthening of ferrite by nano- $\mathrm{VC}$ precipitates results in a decreased extent of strain partitioning.

(4) A simple law of mixtures can reasonably explain the flow stress-strain relationship of DP samples, when the strain/stress partitioning estimated from the DIC analysis is considered.

\section{Acknowledgements}

This research was financially supported partly by a project of "Creation of New Principles in the Multi-scale Design of Steels Based on Light Element Strategy" through the Core Research for Evolutional Science and Technology in the Japan Science and Technology Agency (JST-CREST) and partly by a project of "Research on the Relation between Microstructure and Ductile Fracture in Steel" in the Iron and Steel Institute of Japan (ISIJ), which are gratefully appreciated. NK also thanks a financial support from the Grant-in-Aid for Young Scientists (A) (Grant No. 23686103) through the Ministry of Education, Culture, Sports, Science and Technology (MEXT) of Japan. The authors also thank Prof. Andrew Godfrey at Tsinghua University in China for helpful discussion and language correction.

\section{REFERENCES}

1) M. Takahashi: Nippon Steel Tech. Rep., 88 (2003), 2

2) H. Takechi: JOM, 60 (2008), 22

3) M. Y. Demeri: Advanced High-Strength Steels: Science, Technology, and Application, ASM International, OH, (2013).

4) M. S. Rashid: Ann. Rev. Mater. Sci., 11 (1981), 254

5) H. Paruz and D. V. Edmonds: Mater. Sci. Eng. A, 117 (1989), 67

6) A. T. Davenport, F. G. Berry and R. W. K. Honeycombe: Met. Sci., 2 (1968), 104.

7) R. A. Ricks and P. R. Howell: Acta Metall., 31 (1983), 853.

8) K. Tomita, Y. Funakawa, T. Shiozaki, E. Maeda and T. Yamamoto: Materia Jpn., 42 (2003), 70.
9) T. Shimizu, Y. Funakawa and S. Kaneko: JFE Tech. Rep., 4 (2004), 22.

10) N. Kamikawa, Y. Abe, G. Miyamoto, Y. Funakawa and T. Furuhara: ISIJ Int., 54 (2014), 212.

11) N. Kamikawa, K. Sato, G. Miyamoto, M. Murayama, N. Sekido, K. Tsuzaki and T. Furuhara: Acta Mater., 83 (2015), 383.

12) I. Machida, M. Narita, R. Kureura, M. Morita, N. Aoyagi and M. Sano: SAE Technical Paper, No. 940536, SAE International, Warrendale, PA, (1994).

13) M. Morita, T. Shimizu, O. Furukimi, N. Aoyagi and T. Kato: Materia Jpn., 37 (1998), 513

14) P.-H. Chang and A. G. Preban: Acta Mater., 33 (1985), 897.

15) A. Bag, K. K. Ray and E. S. Dwarakadasa: Metall. Mater. Trans. A, 30A (1999), 1193.

16) T. Matsuno, D. Maeda, H. Shutoh, A. Uenishi and M. Suehiro: ISIJ Int., 54 (2014), 938.

17) Z. Jiang, Z. Guan and J. Lian: Mater. Sci. Eng. A, 190 (1995), 55.

18) K. Hasegawa, Y. Toji, H. Minami, H. Ikeda, T. Morikawa and K. Higashida: Tetsu-to-Hagané, 98 (2012), 320.

19) D. K. Mondal and R. M. Dey: Mater. Sci. Eng. A, 149 (1992), 173.

20) M. Calcagnotto, D. Ponge and D. Raabe: Mater. Sci. Eng. A, 527 (2010), 7832.

21) M. Mazinani and W. J. Poole: Metall. Mater. Trans. A, 38A (2007), 328.

22) K. Park, M. Nishiyama, N. Nakada, T. Tsuchiyama and S. Takaki: Mater. Sci. Eng. A, 604 (2014), 135.

23) H.-C. Chen and G.-H. Cheng: J. Mater. Sci., 24 (1989), 1991.

$24)$ S. S. M. Tavares, P. D. Pedroza, J. R. Teodósio and T. Gurova: Scr. Mater., 40 (1999), 887.

25) K. Hasegawa, K. Kawamura, T. Urabe and Y. Hosoya: ISIJ Int., 44 (2004), 603

26) H. Minami, K. Nakayama, T. Morikawa, K. Higashida, Y. Toji and K. Hasegawa: Tetsu-to-Hagané, 97 (2011), 493.

27) A. A. Sayed and S. Kheirandish: Mater. Sci. Eng. A, 532 (2012), 21.

28) A. Kamp, S. Celotto and D. N. Hanlon: Mater. Sci. Eng. A, 538 (2012), 35.

29) M. Azuma, S. Goutianos, N. Hansen, G. Winther and X. Huang: Mater. Sci. Tech., 28 (2012), 1092.

30) N. Nakada, M. Nishiyama, N. Koga, T. Tsuchiyama and S. Takaki: Tetsu-to-Hagané, 100 (2014), 1238.

31) N. Kamikawa, M. Hirohashi, Y. Sato, Elango C., G. Miyamoto and T. Furuhara: Proc. 4th Int. Symp. on Steel Science (ISSS 2014), ISIJ, Tokyo, (2015), 95

32) Y.-J. Zhang, G. Miyamoto, K. Shinbo, T. Furuhara, T. Ohmura, T. Suzuki and K. Tsuzaki: Acta Mater., 84 (2015), 375.

33) G. Miyamoto, R. Hori, B. Poorganji and T. Furuhara: ISIJ Int., 51 (2011), 1733.

34) T. C. Chu, W. F. Ranson, M. A. Sutton and W. H. Peters: Exp. Mech., 25 (1985), 232.

35) B. Pan, K. Qian, H. Xie and A. Asundi: Meas. Sci Technol., 20 (2009), 062001.

36) G. Krauss: Mater. Sci. Eng. A, 273-275 (1999), 40.

37) N. Fujita, K. Kusumi, K. Matsumura, T. Nonaka and T. Tomokiyo: Nippon Steel Tech. Rep., 103 (2013), 99.

38) Z. G. Cong, N. Jia, X. Sun, Y. Ren, J. Almer and Y. D. Wang: Metall. Mater. Trans. A, 40A (2009), 1383.

39) C. C Tasan, M. Diehl, D. Yan, C. Zambaldi, P. Shanthraj, F. Roters and D. Raabe: Acta Mater., 81 (2014), 386.

40) S. Ohtani, T. Morikawa, K. Higashida and S. Hashimoto: Tetsu-toHagané, 95 (2009), 620.

41) M. Calcagnotto, D. Ponge, E. Demir and D. Raabe: Mater. Sci. Eng. A, 527 (2010), 2738.

42) M. Ojima, Y. Adachi, Y. Tomota, K. Ikeda, T. Kamiyama and Y. Katada: Mater. Sci. Eng. A, 527 (2009), 16.

43) M. Ojima, J. Inoue, S. Nambu, P. Xu, K. Akita, H. Suzuki and T. Koseki: Scr. Mater., 66 (2012), 139.

$44)$ O. Muránsky, P. Šittner, J. Zrník and E. C. Oliver: Acta Mater., 56 (2008), 3367.

45) E. Jimenez-Melero, N. H. van Dijk, L. Zhao, J. Sietsma, J. P. Wright and S. van der Zwaag: Mater. Sci. Eng. A, 528 (2011), 6407.

46) H. Ghadbeigi, C. Pinna and S. Celotto: Exp. Mech., 52 (2012), 1483.

47) H. Ghadbeigi, C. Pinna, S. Celotto and J. R. Yates: Mater. Sci. Eng. A, 527 (2010), 5026.

48) Y. Ososkov, D. S. Wilkinson, M. Jain and T. Simpson: Int. J. Mater. Res., 98 (2007), 664.

$49)$ C. C. Tasan, J. P. M. Hoefnagels and M. G. D. Geers: Scr. Mater., 62 (2010), 835.

50) A. Clair, M. Foucault, O. Calonne, Y. Lacroute, L. Markey, M. Salazar, V. Vignal and E. Finot: Acta Mater., 59 (2011), 3116.

51) Y. L. Su and J. Gurland: Mater. Sci. Eng., 95 (1987), 151.

52) G. E. Dieter: Mechanical Metallurgy, SI Metric Ed., McGraw-Hill Book Company, London, (1988), 289.

53) K. Yamada, H. Nakamichi, K. Sato, K. Yasunaga, T. Daio and S. Matsumura: Tetsu-to-Hagané, 98 (2012), 469. 